\title{
Printfills: 3D printed systems combining Fused Deposition Modeling and Injection Volume Filling. Application to colon-specific drug delivery
}

Vicente Linares, Marta Casas*, Isidoro Caraballo

Department of Pharmacy and Pharmaceutical Technology, Universidad de Sevilla, C/Profesor García González 2, 41012 Seville, Spain.*mcasas@us.es

\begin{abstract}
Three-dimensional printing has become a feasible manufacturing technique for pharmaceutical products providing cheap and accurate freeform systems with a great potential for personalized-dose drugs. Fused Deposition Modeling (FDM) highlights among other 3D technologies due to its low cost and easy to operate but, until now, it has the drawbacks of the low drug loaded and the impossibility to print thermosensitive drugs. So, intermediate processes such as hot melt extrusion are frequently associated with FDM. Here, pharmaceutical dosage forms have been manufactured for the first time with a 3D printer combining two different printing technologies: FDM and injection volume filling (IVF), performing customized extruded scaffolds in which a liquid or semisolid system can be injected at room temperature. A model drug and a $\mathrm{pH}$-sensitive polymer were successfully incorporated during the construction of the extruded backbone of the systems, called printfills (printed systems filled with a liquid or semisolid). SEM microphotographs of printfills show the sealing of the structure in the perimeter and the homogeneity of the colonic film formed in the upper side. Thus, the addition of the $\mathrm{pH}$-sensitive polymer does not need an additional process in a fluidized bed or coating pan. Results from drug release studies performed at different $\mathrm{pH}$ confirm the ability of printfills for colon-specific drug delivery. Therefore, IVF technology complements FDM, solving its main limitations providing an easy, automatized and versatile technology to manufacture tailored drug delivery platforms, avoiding other intermediate processes.
\end{abstract}

Keywords: 3D printing; enteric polymer; drug release; fused deposition modeling; injection volume filling 


\section{Introduction}

Three-dimensional printing is a manufacturing technique that has been introduced in the pharmaceutical field in the '90s [1]. 3D printing includes a wide number of technologies which are based on digitallycontrolled depositing of materials to produce freeform geometries [2]. The application of this technique in pharmaceuticals represents an interesting tool for designing simple, accurate, cheap, structured and personalized-dose medicines. The personalization of the dose could allow the optimization of the dose considering the gender, age, weight, state of the disease and the genetic profile. This aspect gains importance in geriatric and pediatric patients whose physiological needs are very particular, which entails a treatment more in line with their specific needs [3-5]. Several studies have demonstrated the potential of this technology to develop different oral dosing and transdermal systems [6-11]. Thus, this technology provides key advantages over traditional manufacturing of drug delivery and testing systems [12]. However, some drawbacks that have been pointed out include the low printing speed, the lack of quality control procedures for printed systems manufactured at hospitals or pharmacy, or even the possible risk of cyber-attacks on the computer which controls the printing process, jeopardizing the recipe. Moreover, due to its low production and upfront development cost, further studies and an improvement of these technologies are needed to scale up the production in the near future. Notwithstanding the above, from a commercial point of view, 3D printing can be considered as a viable option of manufacture for oral dosage forms. In this sense, USFDA is working in order to frame regulations for 3D printing pharmaceutical products [13].

Among the different 3D printing techniques, fused deposition modeling (FDM) is attracting the interest of researchers in pharmaceutical formulations design due to its low cost, easy to operate and the ability to elaborate hollow objects $[9,14]$. This technology works extruding a polymeric filament with a welldefined and consistent diameter through robotically-actuated nozzles and then solidifying it on a build plate $[14,15]$. As a result, drug release profiles from FDM printed tablets are easily controlled by varying factors such as geometry, polymer selection or drug load [15,16]. However, FDM has the limitation of the impossibility to print thermally sensitive drugs [7,17] and the need to incorporate the drug to the polymeric filament as a previous step of manufacture. Drug loading filaments have been developed firstly by impregnating water-soluble filaments in concentrated alcoholic solutions of drugs, but achieving poor drug loading $(<2 \%)[7,9,18,19]$. Later, hot melt extrusion technique has provided better drug loaded strands [20,21]. These blend filaments have to accomplish with the requirements of the 3D printers (flexibility, circular cross-section and diameter tolerance $(1.75 \pm 0.05 \mathrm{~mm})$ ) needing very often 
the addition of plasticizers to enhance the mechanical properties of the filaments [22]. Regarding the limitation of the extrusion temperature, some researchers have achieved to extrude filaments at $65^{\circ} \mathrm{C}$, but the temperature applied later for printing had to be higher $\left(90^{\circ} \mathrm{C}\right)$, due to the short time that material pass through the heating chamber of the 3D printer [17,22,23].

Dual or multiple extruder 3D printers are also available in the market allowing obtaining composite tablets with different drug profiles [9,24]. Recently, some researchers have modified these dual FDM to include a syringe based dispenser to incorporate liquids or pastes to the systems $[8,25]$. Nevertheless, to our knowledge, the combination of two different 3D printing technologies in a marketed printer to manufacture pharmaceutical formulations has not been already reported. An optimized bioprinter (REGEMAT 3D, Granada, Spain) incorporates two different 3D printing techniques: FDM and Injection Volume Filling (IVF), performing a customized extruded scaffold in which a liquid or semisolid system is injected. IVF allows incorporating solutions/dispersions at room temperature to the extruded scaffold. Until now, this bioprinter has been mainly focused on tissue regeneration applications, adding cells to the extruded system [26]. We hypothesize that the integration of FDM and IVF could offer an easy, automatized and versatile technology to manufacture tailored drug delivery platforms.

The present paper describes the preparation of a new kind of printed pharmaceutical dosage forms that we have called printfills (printed systems filled with a liquid or semisolid), applying for the first time this new technology to the manufacture of dosage forms.

Among modified release drug delivery systems, colon targeting remains a very promising area for protein delivery and the treatment of colonic diseases, such as Crohn's disease, colon cancer or ulcerative colitis. This allows reducing the amount of drug necessary, causing fewer side effects [27]. In addition, several studies have shown that many drugs have a very good absorption in the colon, then the development of new specialized formulations in this region is crucial [27-29]. The manufacture of enteric printed systems has been reported including the coating of 3D printed cores with an enteric polymer (Eudragit L100) in a fluid bed coater [30] or producing enteric filaments by HME with polyacrylic derivatives or hydroxypropylmethylcellulose acetate succinate [31]. In both cases, an additional step in the manufacture of the printed systems is needed to add the enteric polymer.

Thus, combining two 3D printing techniques in the same printer, the addition of the delaying polymer can be carried out with IVF while the scaffold is being developed with FDM as a continuous manufacturing process. Therefore, this printer would provide a saving of energy, time and space, compared to traditional process. 
The aim of this work is to design and characterize colon-specific drug delivery systems manufactured in a simple and automated 3D printer which combines two different 3D printing technologies: FDM and IVF. The model drug and the $\mathrm{pH}$-sensitive polymer will be incorporated at room temperature during the construction of the extruded backbone of three-dimensional tablets. Drug release behavior of these printfills will be analyzed in order to evaluate their ability to control the drug release.

\section{Materials and methods}

\subsection{Materials}

Polylactic acid (PLA) was chosen as biodegradable thermoplastic printer filament for FDM (melting point $220^{\circ} \mathrm{C}$, density $1.25 \mathrm{~g} / \mathrm{cm}^{3}$ ), supplied by Leon3D (Spain). Hydroxypropyl methylcellulose METHOCEL ${ }^{\mathrm{TM}} \mathrm{K} 4 \mathrm{M}$ (Colorcon Ltd., UK) was used as hydrophilic polymer to prepare drug-loaded hydrogels for IVF. Anhydrous theophylline (Acofarma, Spain) has been used as a model drug. Eudragit FS30D (Evonik, Germany) was chosen as delaying release polymer.

\subsection{Methods}

\subsubsection{Preparation of drug printable ink}

HPMC (1\% w/v) gel was prepared by adding powdered HPMC into $100 \mathrm{ml}$ of hot water $\left(90^{\circ} \mathrm{C}\right)$ and thoroughly agitating until a dispersion was formed. The dispersion was cooled with ice and stored in a refrigerator for $24 \mathrm{~h}$ until a smooth homogenous gel, free from air bubbles and aggregates, was formed. Volumes of HPMC gel and ethanol at a ratio of 25:75 (v/v) were thoroughly mixed to form a hydroalcoholic gel. Ethanol is used to retard swelling providing suitable injectability [32]. Finally, theophylline was added until complete dissolution $(20 \mathrm{mg} / \mathrm{ml})$.

\subsubsection{D printing process}

Printfills were manufactured with a REGEMAT 3D V1 printer (Regemat 3D S.L., Spain) with FDM and IVF techniques. The software REGEMAT 3D DESIGNER was used to design the 3D printed systems. Printable gel and Eudragit FS30D dispersion were loaded into two syringes of IVF process, using 0.25 and $0.58 \mathrm{~mm}$ diameter tips, respectively.

The printing settings for FDM were as follows: layer thickness $0.35 \mathrm{~mm}$, perimeter speed $8 \mathrm{~mm} / \mathrm{s}$, infill speed $8 \mathrm{~mm} / \mathrm{s}$ and feeding rate $1.2 \mathrm{~mm} / \mathrm{s}$ to produce printfills with height of $7.35 \mathrm{~mm}$ and diameter of 14 $\mathrm{mm}$.

IVF parameters were: deposit speed $1 \mu \mathrm{l} / \mathrm{s}$, retract speed $1 \mu \mathrm{l} / \mathrm{s}$ and purge $50 \mu \mathrm{l}$ for both syringes.

Printfills were extruded on a glass slide layer by layer, according to the digitally designed object (Figure 1). Extruded scaffolds were formed by 21 layers with 4 sealing perimeters for each one. Firstly, FDM 
nozzle extruded 2 bottom solid layers. In the third layer, the extruder builds parallel lines separated by $1.2 \mathrm{~mm}$ from each other. In the fourth layer, the extruder repeats the process with the difference that the lines are built in a perpendicular direction with respect to the lower ones. So, a quadrilateral mesh of 1.2 $\mathrm{x} 1.2 \mathrm{~mm}$ is created. The process continues similarly until the 18th layer, when extruder automatically moves away and IVF syringe with printable gel injects a volume of $200 \mu \mathrm{l}$ of hydroalcoholic solution in 4 different points digitally defined to ensure the gel distribution inside the scaffold. The porous structure of the internal mesh allows the diffusion of the drug ink. Then, 3 additional layers are built by FDM extruder to complete the scaffold and the second syringe injects $350 \mu \mathrm{l}$ of Eudragit FS30D dispersion into the top layer of the structure.

All the steps including contribution of FDM extruder and the two IVF syringes were automatically performed, building the structure without drying process between them.

Once the structures were completely built, printfills were dried at room temperature to evaporate solvent for $24 \mathrm{~h}$.
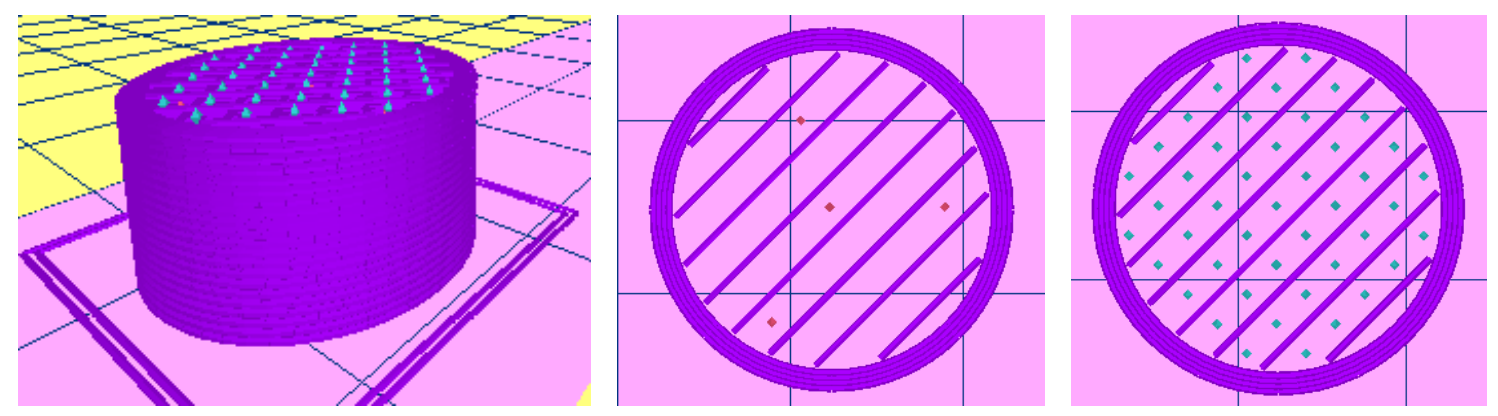

Figure 1. Digital design of printfills with drug represented by red points and the enteric polymer represented as green ones.

In a second series of experiments, printed scaffolds without Eudragit FS30D were manufactured in order to check the drug release profile from these systems, for comparison purposes.

\subsubsection{Physical tests of printed systems}

Printfills were weighted in a precision balance (Scaltec, type SBC31) and thickness and diameter were measured using a digital micrometer (Comecta, SA).

\subsubsection{Scanning electron microscopy (SEM)}

The surface and transversal section of printfills were evaluated in the Microscopy Service of the CITIUS in the University of Seville by using scanning electron microscopy (SEM) with a FEI TENEO electronic microscope (FEI Company, USA), operating at $5 \mathrm{kV}$. Printed tablets were coated with a $12 \mathrm{~nm}$ thin Pt/Pd layer with Leica EM SCD500 high vacuum sputter coater. 


\subsubsection{Determination of drug loading}

The printed system was placed in a volumetric flask (1L deionized water adjusted to $\mathrm{pH} 7.5$ with $2 \mathrm{M}$ $\mathrm{NaOH}$ in order to dissolve the polymer) under magnetic stirring until complete dissolution $(\mathrm{n}=3)$. Samples were withdrawn and filtered through $0.45 \mathrm{~mm}$ filters (Millipore Ltd., Ireland). The concentration of drug was determined by UV-Vis spectrophotometer Agilent 8453 (California, USA) at $272 \mathrm{~nm}[33]$.

\subsubsection{Dissolution testing of printed tablets and modelling}

The dissolution studies were carried out using a USP Apparatus I Sotax AT7 smart (Allschwil, Switzerland) at $37 \pm 0.5^{\circ} \mathrm{C}$ with a rotation speed of $50 \mathrm{rpm}$. The printed systems were first exposed to $\mathrm{pH} 1.2$ for 2 hours. After that, a switch solution was added to achieve $\mathrm{pH} 7.5$ according to a modification of a method proposed by Schellekens et al. (2007) [34]. Filtered samples were withdrawn at specific interval times $(5,15,30,60,90,120,130,140,150,180,240,300,360,420,480,1440 \mathrm{~min})$. The percentage of drug released was measured in a UV-Vis spectrophotometer Agilent 8453 (California, USA) at $272 \mathrm{~nm}$ [33]. The assay was performed in triplicate and sink conditions were met throughout the dissolution test.

Drug release data $\left(\mathrm{M}_{t} / \mathrm{M}_{\infty} \leq 0.8\right)$ were analysed using Microsoft Excel 2010 (Microsoft, Albuquerque, NM, USA) according to zero order, Higuchi (1963) [35], Korsmeyer et al. (1983)[36] and Peppas and Sahlin (1989) [37] equations (1-3):

$\frac{M_{t}}{M_{\infty}}=k t^{1 / 2}$

$\frac{M_{t}}{M_{\infty}}=k_{k} t^{n}$

$\frac{M_{t}}{M_{\infty}}=k_{d} t^{m}+k_{r} t^{2 m}$

where $\mathrm{M}_{\mathrm{t}} / \mathrm{M}_{\infty}$ is the drug released fraction at time $\mathrm{t}$ (the drug loading was considered as $\mathrm{M}_{\infty}$ ), $\mathrm{k}$ and $k_{k}$ are kinetic constants characteristic of the drug/polymer system, $t$ is the release time, $n$ is the release exponent that depends on the release mechanism and the shape of the matrix tested [38], $k_{d}$ and $k_{r}$ are the diffusion and relaxation rate constants, respectively, $m$ is the purely Fickian diffusion exponent for a device of any geometrical shape which exhibits controlled release. 
Determination coefficient $\left(\mathrm{r}^{2}\right)$ was used to test the applicability of the release models, calculated in linear regression for zero order, Higuchi and Korsmeyer equations or quadratic regression for Peppas and Sahlin model.

\section{Results and discussion}

3D printed systems have been successfully performed using FDM and IVF. Figure 2 shows the 3D printer with FDM extruder and the two syringes of IVF used with drug dispersion and Eudragit FS30D, respectively. In order to contain the drug dispersion, the printfill was designed with 2 bottom solid layers and 4 sealing perimeters in each layer. Our preliminary studies of printfills with fewer perimeters showed drug release from the beginning of the dissolution test, even though the homogeneous Eudragit film was present. Therefore, this leads to thinking that there was a radial drug release. Also, perimeter speed, infill speed, feeding rate and printing temperature (FDM) were thought to optimize the coalescence between the perimetric layers in order to obtain a sealed perimeter.
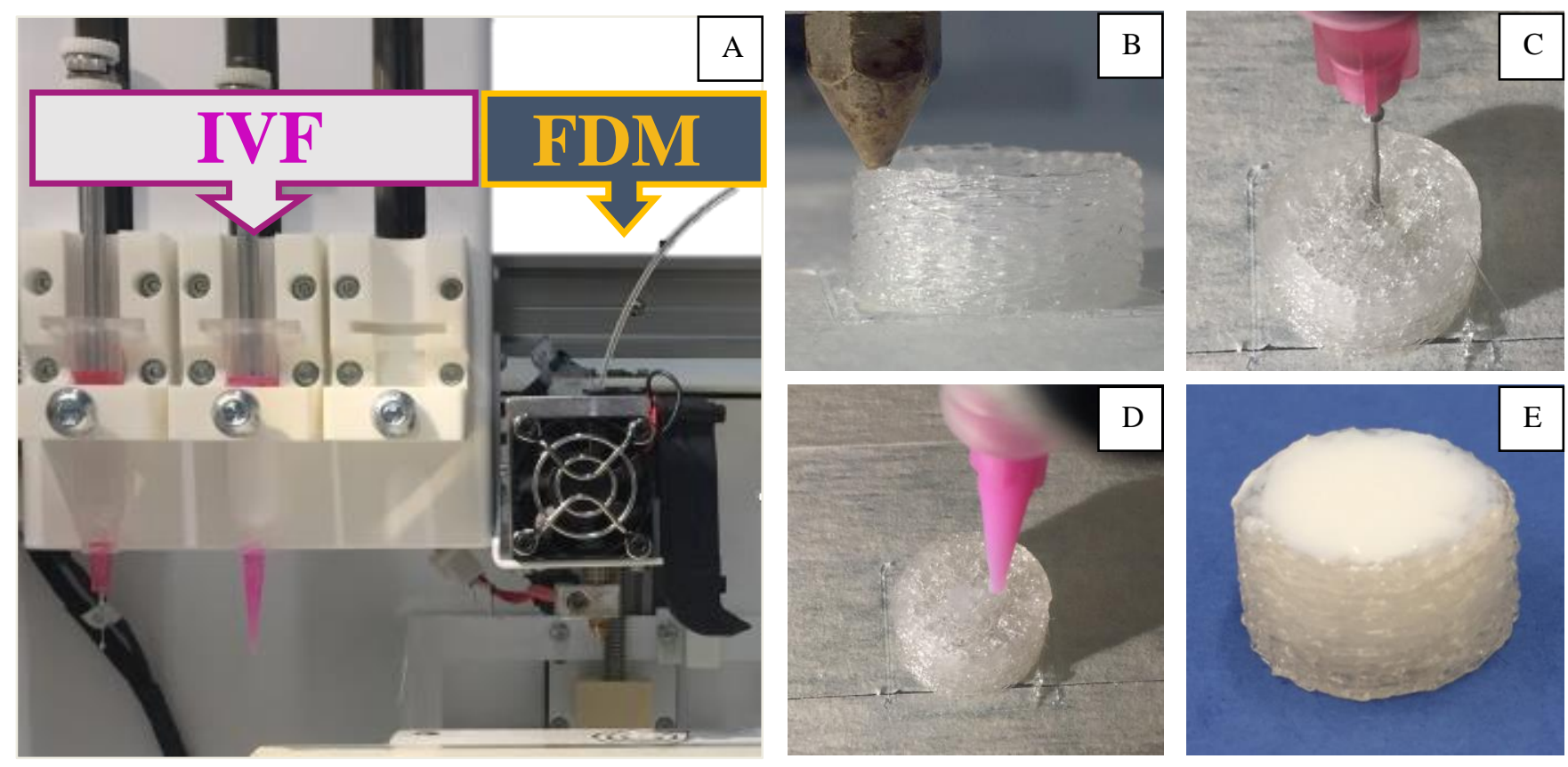

Figure 2. A) 3D printer with FDM and IVF technologies; B) Extruder of FDM technology; C) Syringe of IVF technology injecting the drug-loaded gel; D) Syringe of IVF technology injecting the delaying release polymer; E) Final printfill obtained.

Thereby, drug dispersion was injected at room temperature in PLA extruded structure in the 18th layer.

With a total of 4 injections, this dispersion was distributed by diffusion inside the internal structure. Once dried, theophylline is supposed to be dispersed in the matrix system of the extruded scaffold. On the other hand, Eudragit FS30D was injected at the top layer of the scaffold in all the pores of the mesh, 
in order to ensure that a continuous film was formed. The PLA framework creates a stable structure on which the Eudragit can be supported creating a film on the entire top layer.

SEM microphotographs of printed systems provided useful information about the internal structure of printfills (Figure 3). The sealing of the structure was confirmed by the frontal and transversal section of perimeters (Figures $3 \mathrm{a}$ and $3 \mathrm{~b}$ ), so that, the release of the drug from the printfill depends on the homogeneity and uniformity of the Eudragit FS30D film. The width of the enteric film could be measured, in the narrowest parts, when the delaying polymer is not deposited on the PLA filament, showing values of $149 \pm 0.018 \mu \mathrm{m}$ (Figures $3 \mathrm{c}$ and $3 \mathrm{~d}$ ). Also, there is no direct contact between theophylline and Eudragit, which can be due to the fact that the three first layers below Eudragit do not contain the drug.

In the case of printed systems without delaying release polymer, as their upper side is not sealed, it is possible to observe their internal framework by SEM. Once theophylline dispersion has been completely dried drug recrystallized on PLA filaments, as can be seen in Figures $3 \mathrm{e}$ and $3 \mathrm{f}$.
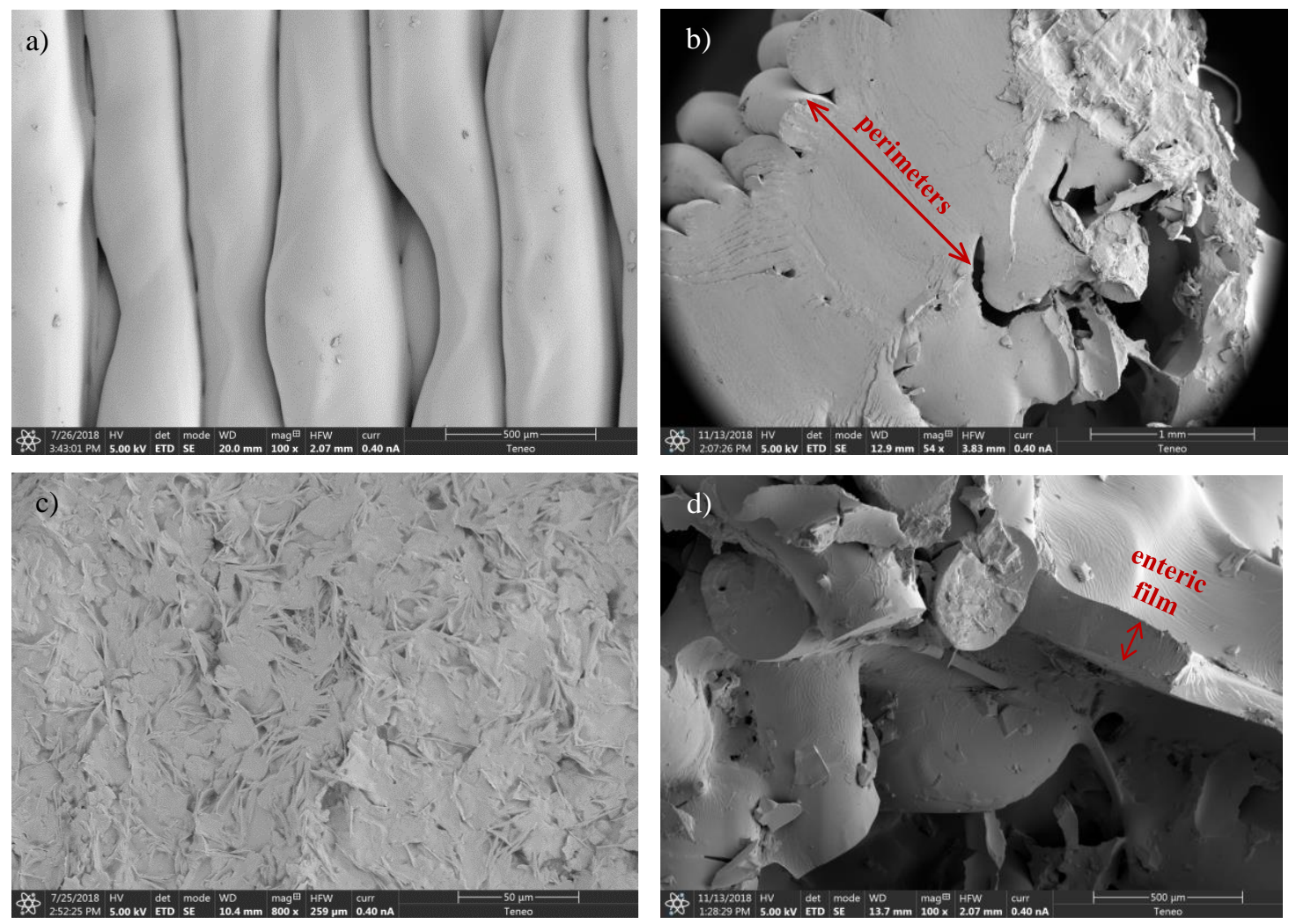

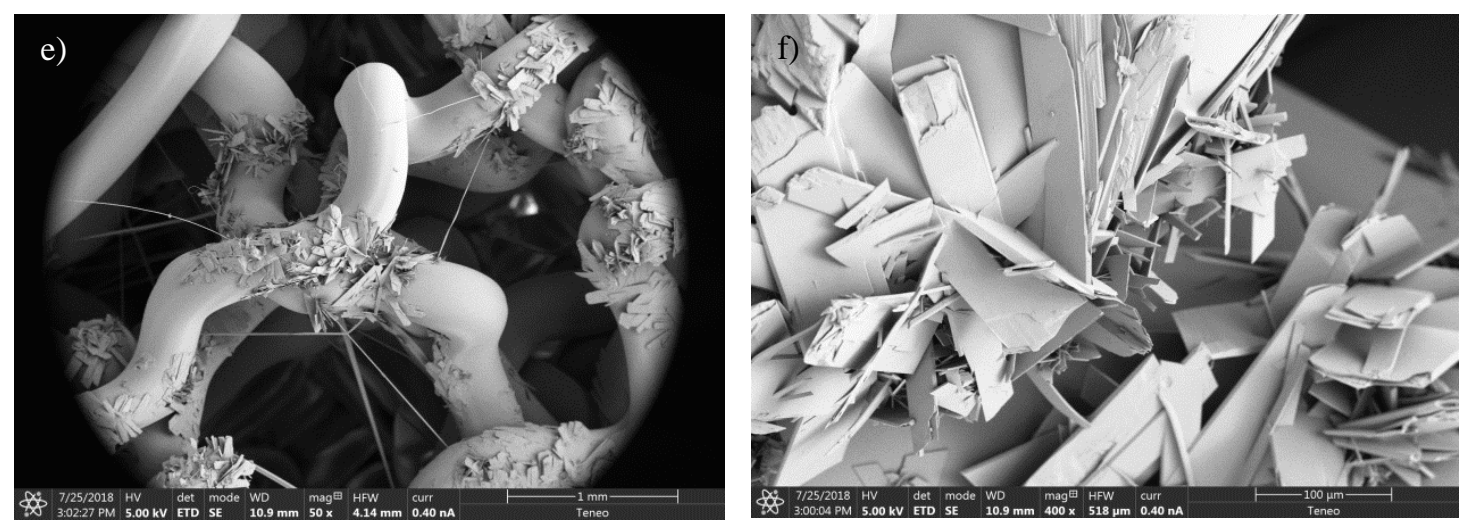

Figure 3. SEM microphotographs of printfills with detail of a) frontal view of perimeters, b) transversal section of perimeters, c) frontal view of enteric film, d) transversal section of printfill with delaying polymer, e) internal mesh of non-colonic printfills with theophylline and f) detail of theophylline crystals on the surface of PLA filaments.

Table 1 shows the weights and dimensions of printfills obtained, according to the digital design. As expected, FDM technology offers an accurate and precise manufacturing of 3D printed systems, obtaining scaffolds able to hold the content from IVF and helping to control the drug release.

Table 1. Physical characteristics of printfills obtained.

\begin{tabular}{|c|c|c|c|c|c|}
\hline \multirow[b]{2}{*}{ Printfill } & \multicolumn{3}{|c|}{ Experimental } & \multicolumn{2}{|c|}{ Theoretical } \\
\hline & $\begin{array}{c}\text { Weight } \\
\text { (mg) }\end{array}$ & $\begin{array}{l}\text { Height } \\
(\mathrm{mm})\end{array}$ & $\begin{array}{c}\text { Diameter } \\
(\mathrm{mm})\end{array}$ & $\begin{array}{l}\text { Height } \\
(\mathrm{mm})\end{array}$ & $\begin{array}{c}\text { Diameter } \\
(\mathrm{mm})\end{array}$ \\
\hline 1 & 1120.8 & 7.508 & 14.819 & \multirow{4}{*}{7.35} & \multirow{4}{*}{14.00} \\
\hline 2 & 1053.8 & 7.330 & 14.827 & & \\
\hline 3 & 1156.2 & 7.300 & 14.982 & & \\
\hline Mean & 1110.3 & 7.379 & 14.876 & & \\
\hline SD & 52.006 & 0.112 & 0.092 & $0.021^{a}$ & $0.619^{a}$ \\
\hline $\mathrm{CV}$ & 4.684 & 1.524 & 0.618 & $0.282^{a}$ & $4.290^{a}$ \\
\hline
\end{tabular}

a, calculated between theoretical and mean of experimental data.

Enteric polymer supposed $9.5 \% \mathrm{w} / \mathrm{w}$ of the printfill weight. This method has the advantage of the addition of the $\mathrm{pH}$-sensitive polymer without the need to use an additional process as a fluid bed or coating pan.

The amount of theophylline injected in the scaffolds was confirmed by drug content assays of the printfills as $4.020 \pm 0.145 \mathrm{mg}$, representing a $0.36 \% \mathrm{w} / \mathrm{w}$ from the total weight of the printfill.

Mean percentages of drug released from printed systems with and without colonic polymer are shown in Figure 4. After $2 \mathrm{~h}$ in $\mathrm{pH} 1.2$, colonic printed tablets released only $2.3 \%$ of theophylline. Once the switch solution was added changing $\mathrm{pH}$ to 7.5 , drug release suddenly increased, suggesting the complete 
dissolution of the enteric film. Around $80 \%$ of drug release was achieved after $8 \mathrm{~h}$ of the dissolution test. On the other hand, printed systems without enteric polymer showed a fast drug release profile from the beginning of the study with more than $60 \%$ of drug dissolved in the first 5 minutes. This confirms the good sealing and tightness of the printfills, forcing the drug to be released through the upper side when the release-delaying polymer is dissolved. Also, homogeneity and uniformity of the Eudragit FS30D film has been confirmed with the prolonged drug release obtained from these printfills respect to the non-enteric ones.

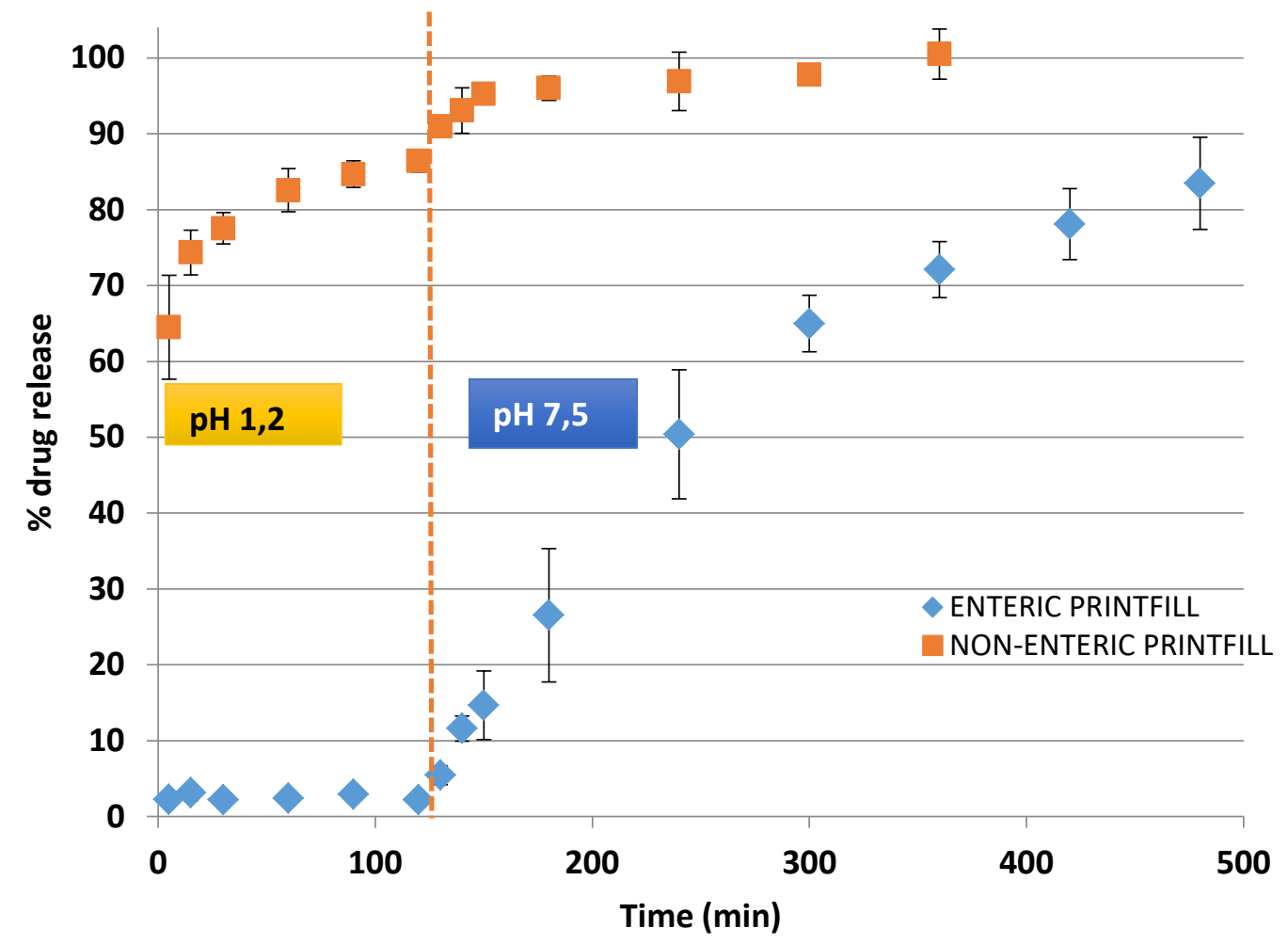

Figure 4. Mean dissolution profiles from both enteric printfills and non-enteric printfills at different $\mathrm{pH}$ values.

Finally, in order to understand the drug release mechanism of the printfills, release data analysis was carried out according to zero order, Higuchi (1963), Korsmeyer et al. (1983) and Peppas and Sahlin (1989) equations. The values of the main parameters are listed in Table 2. The printfills prepared without $\mathrm{pH}$-sensitive polymer showed a fast drug release that did not allow to perform a study of their release kinetics -more than $60 \%$ of drug content was released in less than 10 min-.

With respect to the colonic printfills, the obtained results indicate that, after the lag time, the drug is released with an intermediate kinetics between zero order and diffusional kinetics, as shown by 
Korsmeyer time exponent $(\mathrm{n}=0.8749)$. In general this kinetic is considered as adequate for sustained release. Despite more studies are needed, it could be expected that changing the distribution of the components inside the printfills, could lead to different release kinetics and to tailoring release profiles for concrete therapeutic needs.

Table 2. Mathematical modeling and drug release kinetics from enteric printfills.

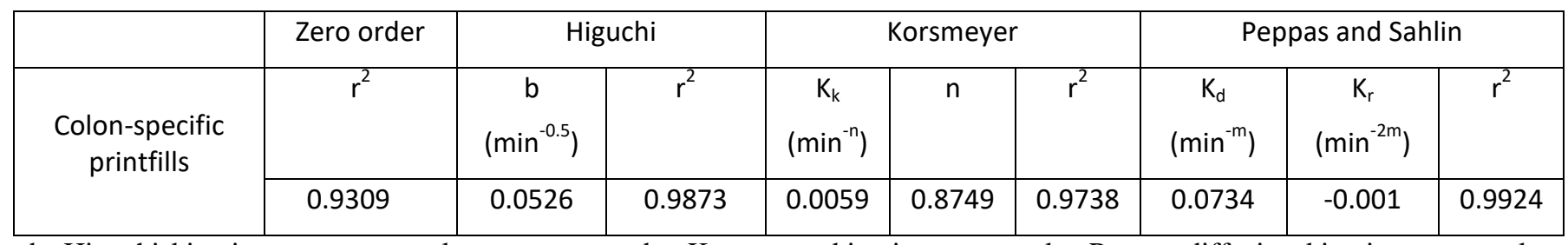

b, Higuchi kinetic constant; $\mathrm{n}$, release exponent; $\mathrm{k}_{\mathrm{k}}$, Korsmeyer kinetic constant; $\mathrm{k}_{\mathrm{d}}$, Peppas diffusion kinetic constant; $\mathrm{k}_{\mathrm{r}}$, Peppas relaxation kinetic constant; $\mathrm{r}^{2}$, determination coefficient.

\section{Conclusions}

Pharmaceutical dosage forms have been manufactured for the first time with a 3D printer combining Fused Deposition Modelling (FDM) and Injection Volume Filling (IVF). The integration of these two techniques allows an easier incorporation of drug/excipient liquid systems to the extruded scaffold at room temperature, avoiding other intermediate processes.

Drug and delaying release polymer dispersions were accurately injected in PLA structure at room temperature. In vitro studies show the ability for colon-specific drug delivery of the performed printfills thanks to the perfect sealing of the scaffold and the homogeneous layer obtained with the delaying release polymer. This way, the advantages of film coating have been obtained without the need of performing an additional process in a fluidized bed or coating pan. Even a more complex pharmaceutical process, as is the partial coating of a dosage form, has been easily performed in one step.

IVF technology complements FDM, solving the main limitations of this technique -as high temperature and difficult drug loading- and thus, providing a versatile platform for drug delivery. Moreover, IVF will allow placing the drug in specific and known sites inside the scaffold, offering a wide spectrum of possibilities in pharmaceuticals for these new dosage forms.

\section{Acknowledgments}

We thank the Ministry of Economy and Competitiveness of Spain (Project MAT2016- 77345-C3-3-P) for financial support. 


\section{References}

[1] B.M. Wu, S.W. Borland, R.A. Giordano, L.G. Cima, E.M. Sachs, M.J. Cima, Solid free-form fabrication of drug delivery devices, J. Control. Release. 40 (1996) 77-87. doi:10.1016/01683659(95)00173-5.

[2] G. Jonathan, A. Karim, 3D printing in pharmaceutics: A new tool for designing customized drug delivery systems, Int. J. Pharm. 499 (2016) 376-394. doi:10.1016/j.ijpharm.2015.12.071.

[3] S.J. Trenfield, A. Awad, A. Goyanes, S. Gaisford, A.W. Basit, 3D Printing Pharmaceuticals: Drug Development to Frontline Care, Trends Pharmacol. Sci. 39 (2018) 440-451. doi:10.1016/j.tips.2018.02.006.

[4] M.A. Hamburg, F.S. Collins, The Path to Personalized Medicine, N. Engl. J. Med. 363 (2010) 301-304. doi:10.1056/NEJMp1006304.

[5] N. Sandler, M. Preis, Printed Drug-Delivery Systems for Improved Patient Treatment, Trends Pharmacol. Sci. 37 (2016) 1070-1080. doi:10.1016/j.tips.2016.10.002.

[6] S.A. Khaled, J.C. Burley, M.R. Alexander, J. Yang, C.J. Roberts, 3D printing of five-in-one dose combination polypill with defined immediate and sustained release profiles, J. Control. Release. 217 (2015) 308-314. doi:10.1016/j.jconrel.2015.09.028.

[7] J. Skowyra, K. Pietrzak, M.A. Alhnan, Fabrication of extended-release patient-tailored prednisolone tablets via fused deposition modelling (FDM) 3D printing, Eur. J. Pharm. Sci. 68 (2015) 11-17. doi:10.1016/j.ejps.2014.11.009.

[8] S.A. Khaled, J.C. Burley, M.R. Alexander, C.J. Roberts, Desktop 3D printing of controlled release pharmaceutical bilayer tablets, Int. J. Pharm. 461 (2014) 105-111. doi:10.1016/j.ijpharm.2013.11.021.

[9] A. Goyanes, A.B.M. Buanz, A.W. Basit, S. Gaisford, Fused-filament 3D printing (3DP) for fabrication of tablets, Int. J. Pharm. 476 (2014) 88-92. doi:10.1016/j.ijpharm.2014.09.044.

[10] S.N. Economidou, D.A. Lamprou, D. Douroumis, 3D printing applications for transdermal drug delivery, Int. J. Pharm. 544 (2018) 415-424. doi:10.1016/j.ijpharm.2018.01.031.

[11] C.P.P. Pere, S.N. Economidou, G. Lall, C. Ziraud, J.S. Boateng, B.D. Alexander, et al., 3D printed microneedles for insulin skin delivery, Int. J. Pharm. 544 (2018) 425-432. doi:10.1016/j.ijpharm.2018.03.031.

[12] M. Alhijjaj, P. Belton, S. Qi, An investigation into the use of polymer blends to improve the printability of and regulate drug release from pharmaceutical solid dispersions prepared via fused deposition modeling (FDM) 3D printing, Eur. J. Pharm. Biopharm. 108 (2016) 111-125. doi:10.1016/j.ejpb.2016.08.016.

[13] P. Khatri, M.K. Shah, N. Vora, Formulation strategies for solid oral dosage form using 3D printing technology: A mini-review, J. Drug Deliv. Sci. Technol. 46 (2018) 148-155. doi:10.1016/j.jddst.2018.05.009.

[14] J. Norman, R.D. Madurawe, C.M. V Moore, M.A. Khan, A. Khairuzzaman, A new chapter in pharmaceutical manufacturing: 3D-printed drug products, Adv. Drug Deliv. Rev. (2015). doi:10.1016/j.addr.2016.03.001. 
[15] G. Verstraete, A. Samaro, W. Grymonpré, V. Vanhoorne, B. Van Snick, M.N. Boone, et al., 3D printing of high drug loaded dosage forms using thermoplastic polyurethanes, Int. J. Pharm. 536 (2018) 318-325. doi:10.1016/j.ijpharm.2017.12.002.

[16] P.R. Martinez, A. Goyanes, A.W. Basit, S. Gaisford, Fabrication of Drug-Loaded Hydrogels with Stereolithographic 3D Printing, Int. J. Pharm. $532 \quad$ (2017) 313-317. doi:10.1016/j.ijpharm.2017.09.003.

[17] G. Kollamaram, D.M. Croker, G.M. Walker, A. Goyanes, A.W. Basit, S. Gaisford, Low temperature fused deposition modeling (FDM) 3D printing of thermolabile drugs, Int. J. Pharm. 545 (2018) 144-152. doi:10.1016/j.ijpharm.2018.04.055.

[18] A. Goyanes, A.B.M. Buanz, G.B. Hatton, S. Gaisford, A.W. Basit, 3D printing of modifiedrelease aminosalicylate (4-ASA and 5-ASA) tablets, Eur. J. Pharm. Biopharm. 89 (2015) 157162. doi:10.1016/j.ejpb.2008.08.018.

[19] A. Awad, S.J. Trenfield, S. Gaisford, A.W. Basit, 3D printed medicines: A new branch of digital healthcare, Int. J. Pharm. 548 (2018) 586-596. doi:10.1016/j.ijpharm.2018.07.024.

[20] A. Goyanes, P. Robles Martinez, A. Buanz, A.W. Basit, S. Gaisford, Effect of geometry on drug release from 3D printed tablets, Int. J. Pharm. 494 (2015) 657-663. doi:10.1016/j.ijpharm.2015.04.069.

[21] A. Goyanes, J. Wang, A. Buanz, R. Martínez-Pacheco, R. Telford, S. Gaisford, et al., 3D Printing of Medicines: Engineering Novel Oral Devices with Unique Design and Drug Release Characteristics, Mol. Pharm. (2015). doi:10.1021/acs.molpharmaceut.5b00510.

[22] A. Melocchi, F. Parietti, A. Maroni, A. Foppoli, A. Gazzaniga, L. Zema, Hot-melt extruded filaments based on pharmaceutical grade polymers for 3D printing by fused deposition modeling, Int. J. Pharm. 509 (2016) 255-263. doi:10.1016/j.ijpharm.2016.05.036.

[23] M. Sadia, A. So, B. Arafat, A. Isreb, W. Ahmed, Adaptation of pharmaceutical excipients to FDM 3D printing for the fabrication of patient-tailored immediate release tablets, 513 (2016) 659-668. doi:10.1016/j.ijpharm.2016.09.050.

[24] H. Kadry, T.A. Al-Hilal, A. Keshavarz, F. Alam, C. Xu, A. Joy, et al., Multi-purposable filaments of HPMC for 3D printing of medications with tailored drug release and timed-absorption, Int. J. Pharm. 544 (2018) 285-296. doi:10.1016/j.ijpharm.2018.04.010.

[25] T.C. Okwuosa, C. Soares, V. Gollwitzer, R. Habashy, P. Timmins, M.A. Alhnan, On demand manufacturing of patient-specific liquid capsules via co-ordinated 3D printing and liquid dispensing, Eur. J. Pharm. Sci. 118 (2018) 134-143. doi:10.1016/j.ejps.2018.03.010.

[26] J. Melchor, E. López-Ruiz, J. Soto, G. Jiménez, C. Antich, M. Perán, et al., In-bioreactor ultrasonic monitoring of 3D culture human engineered cartilage, Sensors Actuators, B Chem. 266 (2018) 841-852. doi:10.1016/j.snb.2018.03.152.

[27] I. Lozoya-Agullo, I. González-Álvarez, M. Merino-Sanjuán, M. Bermejo, M. González-Álvarez, Preclinical models for colonic absorption, application to controlled release formulation development, Eur. J. Pharm. Biopharm. 130 (2018) 247-259. doi:10.1016/j.ejpb.2018.07.008.

[28] T. Ishibashi, K. Ikegami, H. Kubo, M. Kobayashi, M. Mizobe, H. Yoshino, Evaluation of colonic absorbability of drugs in dogs using a novel colon-targeted delivery capsule (CTDC), J. Control. Release. 59 (1999) 361-376. doi:10.1016/S0168-3659(99)00005-X. 
[29] Y. Masaoka, Y. Tanaka, M. Kataoka, S. Sakuma, S. Yamashita, Site of drug absorption after oral administration: Assessment of membrane permeability and luminal concentration of drugs in each segment of gastrointestinal tract, Eur. J. Pharm. Sci. 29 (2006) 240-250. doi:10.1016/j.ejps.2006.06.004.

[30] A. Goyanes, H. Chang, D. Sedough, G.B. Hatton, J. Wang, A. Buanz, et al., Fabrication of controlled-release budesonide tablets via desktop (FDM) 3D printing, Int. J. Pharm. 496 (2015) 414-420. doi:10.1016/j.ijpharm.2015.10.039.

[31] A. Goyanes, F. Fina, A. Martorana, D. Sedough, S. Gaisford, A.W. Basit, Development of modified release 3D printed tablets (printlets) with pharmaceutical excipients using additive manufacturing, Int. J. Pharm. 527 (2017) 21-30. doi:10.1016/j.ijpharm.2017.05.021.

[32] S.A. Khaled, J.C. Burley, M.R. Alexander, J. Yang, C.J. Roberts, 3D printing of tablets containing multiple drugs with defined release profiles, Int. J. Pharm. 494 (2015) 643-650. doi:10.1016/j.ijpharm.2015.07.067.

[33] M. Casas, Á. Aguilar-de-Leyva, I. Caraballo, Towards a rational basis for selection of excipients: Excipient Efficiency for controlled release, Int. J. Pharm. 494 (2015) 288-295. doi:10.1016/j.ijpharm.2015.08.002.

[34] R.C.A. Schellekens, F.E. Stuurman, F.H.J. van der Weert, J.G.W. Kosterink, H.W. Frijlink, A novel dissolution method relevant to intestinal release behaviour and its application in the evaluation of modified release mesalazine products, Eur. J. Pharm. Sci. 30 (2007) 15-20. doi:10.1016/j.ejps.2006.09.004.

[35] T. Higuchi, Mechanism of sustained-action medication. Theoretical analysis of rate of release of solid drugs dispersed in solid matrices, J Pharm Sci. 52 (1963) 1145-1149.

[36] R.W. Korsmeyer, R. Gurny, E. Doelker, P. Buri, N.A. Peppas, Mechanisms of solute release from porous hydrophilic polymers, Int J Pharm. 15 (1983) 25-35.

[37] N.A. Peppas, J.J. Sahlin, A simple equation for the description of solute release. III. Coupling of diffusion and relaxation, Int J Pharm. 57 (1989) 169-172.

[38] P.L. Ritger, N.A. Peppas, A simple equation for description of solute release I. Fickian and nonfickian release from non-swellable devices in the form of slabs, spheres, cylinders or discs, $\mathrm{J}$ Control. Release. 5 (1987) 23-36. 